\title{
Discussion on Modern Business Marketing Mode of Traditional Folk Arts and Crafts
}

\author{
$\mathrm{Nan} \mathrm{Xu}$ \\ Eastern International Art College \\ Zhengzhou University of Light Industry \\ Zhengzhou, China
}

\begin{abstract}
-traditional culture has immeasurable commercial value and it is the reserve force that moves toward industrialization. As cultural industry, the most important thing is to base on preserving traditional culture, use rich forms to grasp the requirements of consumers and supplement necessary marketing methods to finally create competitive cultural brands. This article discusses from the relationships between traditional handicrafts and modern marketing, deeply understands the present situation that modern handicrafts lack innovation and they are continuously devalued, rationally analyzes the reasons of these results from the perspective of history, and then puts forward the opinion that make corresponding changes for marketing methods to reach the objectives of inheriting traditional handicraft and prospering regional economy.
\end{abstract}

Keywords—traditional handicrafts; marketing mode; branding

\section{INTRODUCTION}

With the acceleration of urban modernization, under the impact of modern industrial industrialization, traditional handicrafts show different forms and development tendency. Some are replaced and become the collectibles in museums; some combine with industrial civilization and get on the track of mass production; some gradually lose their practicability but the aesthetic property takes the lead; some become fashion goods that lead the new trend because their practical and decorative potential advantages are better discovered. All in all, traditional handicraft industry faces the problem of modern transformation. One reason is the involvement of modern technology; the other reason is the contraction of the market and there aren't successors. Therefore, it is the important category of our present research to rescue and protect national folk craft culture and protect the inheritance and development of national traditional culture.

Handicraft is the typical combination of technology and art. In the nearly one hundred years of development, science and technology civilization brings forth the outbreak industrial revolution; machinery production and the strict division of labor in the system restrict workers in the local, single, repeated and boring manipulation; the win-win relationship of technology and art is disintegrated thoroughly. The result of this change is the appearance of design art and modern industrial art. Meanwhile, traditional handicrafts are faced with serious challenges; the market of handicrafts appears serious survival crisis. What should traditional handicrafts do? First of all, they must clearly see the weaknesses of themselves, adopt the good points and avoid the shortcomings to correctly find their location; and then develop markets of their own to determine new operation mechanism of virtuous cycle. Maybe in this aspect, we haven't formed clear and correct understandings, so some faults appear and lead to the situation that the undertaking of crafts cannot recover after a setback in nowadays. For example: we have put forward the slogan of practical crafts to anew go back to the field of production and market of daily necessities, but practice has proved that it is not a sound strategy. The production characteristic of craft is handicraft. Under the background of development of mechanical automation and computerization, on the contrary, the value orientation of handicrafts will rise. Of course, it must guarantee that the pure handicraft production has innovative handicrafts. For example: Once people immoderately met the requirements of ordering goods under bubble orders, even used half mechanization and production line to pretend to be handicraft labor; the result is bad of course. These things happened in the 1980s when the import and export of traditional handicraft articles reached the peak, but before long it appeared depression, let us cannot meet the requirements of international market for modern handicraft. Until today, it is difficult to see the prospect that it recovers rapidly.

\section{BRANDING}

Branding is an ability to endow product and service with a brand. The essence of branding is to create difference to make products or services different from others. The essence of a brand should include its value, culture and individuality. It is very important for branding management of traditional handicrafts to inherit and popularize traditional handicrafts and embody commercial value. The advantages of branding are that it helps to promote the product distribution and set up enterprise image; the registered brand (registered trademark) can protect legitimate interests of enterprises; brand helps to restrict misconducts of enterprises; brand helps to expand the product assortment; brand helps consumers to recognize, identify and pick out and buy 
commodities; brand helps to maintain the interests of consumers.

\section{A. Exploration on Branding Business Pattern of Traditional Handicrafts}

1) Unique value of local middle and small-sized enterprises. Various regions in Central Plains not only have tradition, technology and skill of handicraft manufacture, but also have the livelihood verified by unique aesthetic consciousness and wisdom. It has profound significance for handicraft manufacture and regional development by using branding to help and support local middle and small-sized enterprises. "The unique values of local middle and smallsized enterprises" can be divided into the following aspects:

The quality of craftsman: It is the skill of craftsman. It contains traditional and modern characteristics nourished by native land. There are rich and natural handicrafts made by skillful craftsman. They have strict requirements for themselves and do special researches to create high quality handicrafts.

Practical beauty: It refers to the beauty formed in the process of everyday use. This "sincerity" brought by manufacturers for practical beauty and hope favored by users will surpass the age and national boundaries to add bright colors for people's life.

Local development: Different regions have colorful nature, culture, tradition and life. Local middle and smallsized enterprises support local nature, tradition, culture and life through their own efforts. Full of sense of pride, they pass on it to the next generation for the sharing of people from all over the world.

2) Evolution. Local middle and small-sized enterprises are in the most changeful market. They must continuously "evolve" products and services of their own. The directions of its "evolution" include the following aspects:

In modern life, they need to give play to the feeling of freshness that has practicality and beauty; improve the charms of products, service and career to make them can be used in domestic and foreign markets; in the career of real products and service, keep consistency and continuity, make the "unique value of local middle and small-sized enterprises" become tangible things.

3) New traditional creation. It should use the idea of "new traditional creation", make the "unique value of middle and small-sized enterprises" continuously "evolve", and devote to the products and services that can be used in modern life and domestic and foreign markets; establish local brand on this basis, strengthen the business foundation to make contribution to enlivening local economy.

\section{B. Research on Branding of Traditional Handicrafts}

In modern life, they need to give play to the feeling of freshness that has practicality and beauty; improve the charms of products, service and career to make them can be used in domestic and foreign markets; in the career of real products and service, keep consistency and continuity, make the "unique value of local middle and small-sized enterprises" become tangible things. It should use the idea of "new traditional creation", make the "unique value of middle and small-sized enterprises" continuously "evolve", and devote to the products and services that can be used in modern life and domestic and foreign markets; establish local brand on this basis, strengthen the business foundation to make contribution to enlivening local economy.

From the perspective of the market, culture and business operation gradually becomes mature. Each enterprise and public institution, even individual pays more and more attention to the unique cultural value of its own. If they ignore the practical value of handicraft and simply regard it as service commodity, a piece of handicraft cannot be appropriate for various industries. Handicraft should combine with market requirements. The customized design philosophy is gradually accepted by the market. People require "reserving differences" instead of "seeking common ground" and they need cultural concept and market positioning different from others. Only in this way can modern handicrafts better meet the requirements of individuals or business and have the soil of continuous innovation and development after being accepted by the market gradually and getting feedback from the market.

\section{MARKETING ENVIRONMENT}

\section{A. Ways of Marketing Promotion of Traditional Handicraft}

Build professional sales team. Profit is the fundamental point for the survival of enterprise. Sale is the only way to make profits. If there isn't professional sales team and the enterprise only waits passively instead of selling actively, the profit will be greatly reduced. Therefore, first of all, enterprises can employ one or two professional sales personnel to concentrate on the sales of traditional handicrafts and business management.

- Establish diversified marketing channel. Generally speaking, most enterprises that sell traditional handicrafts have the characteristics of small amount of order and low profits. It is mainly because the marketing channel is single. They should make great efforts to expand other marketing channels.

- Find professional companies or shops to sell;

- Network sale;

- Cooperate with tourism companies concerning foreign affairs to set up scenic spots of Chinese national intangible cultural heritage;

- Cooperate with auction companies to hold unscheduled activities of auction of handicrafts;

- Make personalized customization for high-end customers. 


\section{B. Operation Management Environment of Traditional Handicraft}

Establish and improve operation management system of enterprises. Take Shanghai Li Hui Tapestry Art Limited Company as an example. Because it was a traditional stateowned handicraft production enterprise, and the internal operating system in the company is loose and the scale of the company is smaller and smaller, the company management is gradually replaced by personal management. In view of this, Chinese traditional handicraft enterprises that have similar business background should establish and improve basic systems of business operation such as internal operation management system and enterprise profit distribution system.

Establish talent development team. Many traditional handicraft enterprises have serious problems of aging of talents. Therefore, they should establish talent development team as soon as possible and steady older employees at the same time wholeheartedly cultivate young and middle-aged talents.

\section{Marketing Strategy Positioning of Traditional Handicraft}

Take the path of best quality and pay attention to continuous development in the field of high-grade handicraft. No matter for Shanghai Li Hui Tapestry Art Limited Company or any other enterprise that manage traditional handicraft, if they have the ability and strength to make highgrade handicrafts, even though the manpower and material resources of the enterprise are very limited, they should stick to the positioning of best quality.

Emphasize the characteristics of traditional handicrafts and pay attention to establishing self-owned brand. High additional value is often accompanied with unique characteristics and high-grade brand. Therefore, traditional handicraft enterprises must highlight the characteristics of intangible cultural heritage of Chinese traditional handicrafts, especially should give prominence to the characteristics of original works and create self-owned brand.

\section{PRosperous Regional ECONOMY}

With the upsurge of worldwide cultural consumption and the prosperity of tourist industry, the traditional handicraft industry with local characteristics in various countries in the world is recovering. Protecting traditional industry has great significance in prospering regional economy. The handicraft in China is famous throughout the world for its long history, rich categories and exquisite craftsmanship, but under the market impact, it is faced with all kinds of crisis. According to international development tendency and experience, it is necessary to seize the opportunity to develop tourism handicrafts with local characteristics to prosper regional economy. From the perspective of lessons drawn from others' mistakes, in the course of more than twenty years of reform and opening up, the speed of development in southeastern coastal areas substantially exceeds the practice of the mainland. It reveals the following two problems:
Firstly, long history is not equal to brilliant reality. The region that is developed at the earliest within China and has the longest history is Yellow River basin, and then they are Huai River basin and Yangtze River basin. The southeastern coastal areas are developed later than them. They were regarded as wild places until Tang dynasty. However, after the reform and opening up, southeastern coastal areas rise rapidly. The speed of development is far ahead of any other area except for Yangtze River delta. They also create regional economic development models such as "Pearl River Delta model" and "Wenzhou model" that attract the attention of the world. It clearly tells us that the long history can only represent the past. It cannot represent the present, let alone the future.

Secondly, culture of great splendor is not equal to advanced consciousness. The culture created in ancient China is bright and colorful. They are mainly located in surrounding areas of the six ancient capitals, namely the Guandong area around Xi' an, areas in Central China around Luoyang and Kaifeng, lower reaches of the Yangtze River around Nanjing, the Easter Areas of Zhejiang around Hangzhou, and areas in North China around Beijing. Among them, although northern areas gather various cultural objects together, because they are located in the heartland of ruled by the government, with strict control from feudal regime, the passive components have greater influences on the concept of Confucian cultural tradition. People's thinking tends to be conservative. Although the historical culture in southeastern coastal areas is inferior to the culture in the above areas, because it is far away from the central government, with relatively weak feudal regime and relatively loose ideological imprisonment, the Yongjia School that advocates "moral and profit exist simultaneously" and "moral and profit implement simultaneously" can produce and develop there; and the maritime commerce culture in Fujian and Guangdong that has the characteristics of paying attention to commerce and pursuing profits also can be formed and spread there. Therefore, under the same blue sky and in the same age of reform and opening up, in the face of the same policy to enrich the people, southeastern coastal areas can be the first to seize the opportunities and walk in the forefront of the country on development. It is obvious that splendid culture can only represent the past. It cannot represent the present, let alone the future.

At present, many areas in the central and western regions are using local excellent cultural heritages to invite investment and develop economy through organizing various activities such as cultural festivals and tourism festivals. This is just the "culture and economy enhance each other's beauty" said by people. Its positive role should not be underestimated. However, after detailed analysis, it is observed that: most of the culture is local folk culture, including dress culture, entertainment culture, food culture and tea and wine culture, rarely referring to deep-seated problems of concept of cultural tradition. Therefore, although cultural activities in these areas grow vigorously and the markets of famous special local products are crowded with people, the growth rate of overall economic 
strength is below expectation and still lags behind eastern regions. Therefore, in order to achieve rapid economic development, the central and western regions must carefully survey the local long-standing concept of cultural tradition. Firstly of all, they must inherit and carry forward the quintessence, criticize and overcome the dross to eliminate traditional concepts that go against the development and progress. Meanwhile, they should continuously learn advanced thoughts of other areas. They should learn the enterprising spirit that daring to be the first, the brave business spirit and spirit of bearing hardships, the way of management that can do both big and small business of Wenzhou people in Zhejiang province, in order to create new concept and spirit of the time that suit the development of regional economy. Only in this way can it gives full play to the economic potential contained in central and western regions, turns resource advantages into economic advantages, and gradually narrows the gaps with eastern areas on development, finally realizes the ambitious goal of common prosperity of the whole country.

In the past, for the traditional arts and crafts industry, we focus on the protection and then seek development on this basis. Because they are excellent cultural heritage and cultural tradition, we make great efforts to protect them. It is easy for us to fall into the thinking model and mode of operation that we just protect it without seeing other things. It restricts the possibility of extension of value chain of traditional arts and crafts industry to some extent. In order to survive and develop under the present era, traditional arts and crafts must have the ability in creating value and meeting the market requirements. On the contrary, traditional arts and crafts will have increasingly weak market capacities on industry, enter the rank of "preservation of cultural relics", or become vulgar, cannot attract funds and personnel for industrial creation, and then it is difficult for them to make breakthrough on design, production and marketing. It is the fundamental solution to develop the enormous commercial value contained by traditional arts and crafts industry. Using the perspective of modern business operations to regard arts and crafts, using rich creativity and imagination to develop the enormous business opportunities contained by traditional arts and crafts is to use development to promote the protection. It means developing people's internal requirements for traditional arts and crafts products to create enormous commercial value.

\section{REFERENCES}

[1] Zhang Jianshi, Yang Zhengwen. Protection of Cultural Resources of Traditional Handicrafts in Southeastern Ethnic Minorities [J], Journal of Southwest University for Nationalities (social science edition), 2004

[2] Qiu Xiaomin, Gao Jianping. Discussion on Developing the Innovation of Cultural Industries and Cultural System [J], Academic Forum, 2005

[3] He Gensheng, Wan Fubin. Do Not Let Modernization Submerge National Treasures [N], Science Times, 2005

[4] Li Yanzu. Tangible and Intangible: Protection and Development of Traditional Arts and Crafts [N], Literature and Art Studies, 2006

[5] Lin Yusheng. Creative Conversion of Chinese Tradition [M], Beijing: Sanlian Publishing House, 1997
[6] Liu Zongyue, Translated by Xu Yiyi. Craft Culture [M], Beijing: China Light Industry Press, 1991

[7] Zhang Fuye, Sun Jianjun, Trip to Traditional Handicrafts [M], Shenyang: Liaoning Fine Arts Publishing House, 2001

[8] Kong Fanchang. Value Trend and Design of Modern Handicrafts [J], Art Observation, 2006(01)

[9] Zhang Fuchang, Tang Hao. Develop Local Distinctive Tourist Products and Prosper Regional Economy, Journal of Wuxi University of Light Industry, the second phase in 2001 